\title{
Editorial: SexPolitics and Rights in Development
}

\author{
WENDY HARCOURT
}

Assembling on the first day of the Institute of Development Studies workshop at the University of Sussex, Brighton on 'Sexuality and the Development Industry' we were all asked to introduce ourselves. The room soon filled with the voices of people explaining their lives and histories. But we were not being called upon to identify ourselves by our country, our organization, our academic or activist pedigrees, the usual fare for international workshops. Instead we were asked to engage immediately with others as heterosexual, gay, lesbian, trans, as parents, as singles with various histories as differently engaged sexual persons. We were asked to be out and honest and enjoy it. Going to the heart of our identifies, we were turning private into public. With such a beginning the meeting was charged with energies that bowled us along during two days of intense discussion where what are usually silenced issues emerged as crucial, challenging and exciting ones for development.

Development volume 52 on culture and identity starts boldly with sexuality and development as its first theme. The aim of the journal issue is to examine international development's connections with sexuality, and look for more creative and constructive means of engagement. The articles are based on the dialogue that buzzed among activists, donors and academics at the workshop held in April 2008. The journal issue sets out why sexuality is an important issue to address and explores why the development has failed to constructively take on the issue in the past as well as to propose how to do it better.

The key themes of the journal are: how does mainstream development imagine and deal with sexuality? What impact is development having on people's sexualities? And most importantly, the journal pinpoints the strategies for a more constructive engagement in development around issues such as heteronormativity, pleasure, lesbian gay bisexual and trans (LGBT) rights, sex work, male vulnerability, funding and sexual rights.

It is in striking context to the international media that sexuality is rarely addressed in international development. Newspapers are full of spicy discussions related to sex work, global sex tourism and protests. We read reports of married couples in Malindi, Kenya splitting for the high tourist season to pick up rich white lovers and then coming back and pooling the gains made in order to pay for children's schooling and health in the low season. ${ }^{1}$ Gay rights parades in Delhi are on the front page in newspapers around 
the world. ${ }^{2}$ The migrants who come to rich cities in Europe to sell sex of all types are part of modern cosmopolitan life and their lives are splashed across the media regularly. It is curious that in development none of this sexual behaviour appears, instead there is the assumption that, if we discuss sex at all, it is in relation to deviance, oppression and coercion. Although the ground is shifting, development assumes heterosexuality is the only normal, sexual behaviour, and even that should only be spoken about if there are problems, side stepping issues of sexual difference, pleasure and sexual identities.

It continues to be very hard to break the taboos around speaking of sexuality in development. The topic of sexuality causes frictions, frissons and even rifts among people who might otherwise share a common culture and goals.

This journal issue aims to open up the debate on sexuality and development by challenging the ambivalence around pleasure and sexual choice as subjects of development. The argument of the journal is how the focus of development discourse on sexuality as a topic associated with problems: oppression, illness, violence and abuse obscures the fact that the pursuit of sexual pleasures is pivotal to social and cultural arrangements and behaviours, not all of which are heterosexual. Heteronormativity is a mouthful and a term many readers may not have heard. Charmaine Pereira, Andil Gosine, Jaya Sharma and Amy Lind give important insights into how institutionalized, normative heterosexuality determines sexual behaviours of those within its boundaries as well as marginalizing those outside them. Heterosexuality is the dominant, normative gender relationship that orders sexual life as well as domestic and extra-domestic divisions of labour and resources.

Heteronormativity orders much of our lives and blinds us to many other facets of sexuality. It is a powerful concept that we need to understand as it is embedded within mainstream development economic and social policy and can impose oppressive stereotypes on all men and women and lead to discriminatory policies that run contrary to human rights. If development is to to understand sexuality as a profoundly important issue in development. Heteronormativity in development needs to shift and indeed is being forced to shift. The global HIV and AIDS pandemic has opened up discussions on different forms of sexuality, desire and behaviour. The mobilizing of resources to respond to HIV and AIDS has given the space for the once-marginalized identity groups, identifying LGBT to speak about their lifestyles and sexual choices.

The articles feature the major trends in sexual rights and the political advocacy work of 'SexPolitics'. Under the umbrella of human rights, sexual rights must include the right of all persons to sexual fulfilment and to freedom from coercion, discrimination and violence around sexuality, whatever their sexual orientation or sexual identity. ${ }^{3}$ Sexual rights advocates challenge the idea of sexuality as necessarily bad and suspect and rather encourage us to see sexuality as part of positive rights and pleasure. The authors underscore that celebrating or opening possibilities for pleasure can be empowering and affirming, especially for those who are discouraged from enjoying their sexuality, particularly many women, people living with HIV and AIDS, people with disabilities, LGBT people. As Akshay Khanna and Giuseppe Campuzano show sexual rights recognizes that many people do not fit neatly into categories of male and female such as the hijras in South Asia, the travesti in Latin America, ${ }^{4}$ the tommy boys and lesbian men in Africa, the ladyboys in Thailand, the third spirit among indigenous Americans and globalized identities of queer and trans (transsexuals) and intersex people with bodies that genetically and physiologically combine male and female.

The recognition of all these forms of sexual identity and gender pluralities challenges the accusation that sexual rights is a western concern. Liz Amado speaks of sexuality in Muslim society, Xiaopei He of lesbians and trans in China, Khanna about trans in India, Nadine of lesbian rights in Lebanon. Although we know full well that there can be high social costs involved in activism that pushes for sexual rights, from imprisonment to death in some parts of the world, importantly as the conversation hosted by Cheryl Overs indicates 
with a uniquely sassy humour, these articles are testimonies not of victimization but of empowerment and change.

One of the strongest messages in the journal is the importance of HIV and AIDS in terms of changing attitudes to sexuality within development. HIV and AIDS pandemic reveal that in all countries there are men and women who engage in non-heterosexual sex and multiple-partner sex. Deevia Bhana and Rob Pattman, Karin Lenke and Mathilda Piehl show how ways to counter HIV and AIDS help to create spaces that can break the traditional silence around same sex encounters and queer sex and has shaped the cultures and politics of global gay movements. Camilo Najlis and Andy Seale also show how the political struggle for sexual rights is part and parcel of the struggle to find funds, appropriate treatment and resources for people living with HIV and AIDS. Sexual rights groups such as HIV + women, men who have sex with men and sex workers are often the ones providing services for those living with AIDS, helping with dying, reaching out to prisoners, young people, drug addicts and others who are marginalized.

The journal issue is full of innovative and creative ideas around sexuality, from challenging heteronormativity within development aid organizations to organizing a fake wedding for three in China to new approaches to sexuality and development by 'The Pleasure Project' based in the UK. Coordinated by Wendy Knerr and Anne Philpott, The Pleasure Project is a transnational education project that aims to "build bridges between the pleasure sex industry and the safer sex world by avoiding negativity and by ensuring that erotic material include examples of safer sex' (www. thepleasureproject.org). As Wendy Knerr explains, the Pleasure Project aims to make sex safer by addressing one of the major reasons people have sex: the pursuit of pleasure instead of focusing on negative and disease-focused programmes.

The journal celebrates positive approaches to sexuality and sexual rights, but that it is not to deny the pain and misunderstanding bound up in the conversations, silences, struggles and questions that deeply ingrained sexual injustice brings out. Difficult as it is, we cannot afford to ignore the issue of sexuality in development whatever our lifestyles, histories, desires, hopes and fears. Indeed some would argue it is not a question of ignoring. As Andil Gosil points out that in constructing sex as a problem in development, an important rationale is provided for development interventions to control sexualities of peoples of the global South. He argues:

Development schemes have imposed heterosexuality, marginalized sexual minorities, and ignored the impact of sexuality-based discrimination, as well as the significance of sexual pleasure to the well-being of people of the Global South. We need to pay more critical attention to how the articulation of sex as problematic not only works to validate and legitimate intensified regulation of bodies and sexual practices, but also harnesses these anxieties about sex to further extend and advance imperialist ambitions.

The challenge is how to build sexual rights as discourse and advocacy, transform ideals such as erotic justice and sexual freedom into realities, identify agents and important decision-makers, and create shifting spaces for different voices to be heard. Sexual rights seeks to counter the myriad injustices built into the social, legal and economic systems, which control and police sexuality, culture, gender and sexual minorities. Sex Rights provides an important critical perspective from which to challenge development.

As the first issue on culture and identity, volume 52, no. 1 makes visible the many different forms of sexual identity and cultural practices around sexuality, presenting sex as a source of positive expression of self and community rather than as a dangerous and taboo topic for development. As with the journal issues to come it challenges commonplace assumptions and underlines the fluidity culture and identity. The other issues in the volume will continue to look at how concepts of culture and identity underpin political and economic decisions. The next issue, volume 52, no. 2 on 'power, movements, change', features the dynamic cultures and identities in people's movements, specifically women's movements, produce as a report from the AWID Forum on the power of movements. The third issue, volume 52, no. 3 'beyond markets', presents a critical look at our 


\section{Development 52(1): Upfront}

globalized culture of consumption driven by markets that has fuelled the current financial, climate and food crises. The last issue, volume 52, no. 4 on 'xenophobias, culture and identity', explores the racism and neo-colonialism that lurks below the surface of many social and economic conflicts that cannot afford to be ignored by development policy.

\section{Notes}

1 See http://www.eastandard.net/mag/InsidePage.php?id = 1143990594\&cid = 349\&.

2 See The Guardian article at http://www.guardian.co.uk/world/2008/jun/30/india.gayrights.

3 See varied definitions of sexual rights in the Sexual Rights Charter of the Women's Health Project South Africa; IPPF 'Charter on Sexual and Reproductive Rights, Health, Empowerment and Accountability'; HERA; and World and Association of Sexology.

4 The hijras may be born intersex or male and portray themselves as feminine and live in kinship groups of other hijras, usually but not necessarily they have male lovers and sometimes undergo surgery. Travesti in Latin America are generally born with male bodies and grow up to dress and act feminine; they see their own gender identity as male or travesti and often invest in surgery to increase the voluptuousness of their bodies. 